\title{
Design of Carbon Monoxide (Co) Pollutant Gas Detection and Monitoring System Using Mobile Detection Model Based on Internet of Things (IoT)
}

\author{
Muhammad Yusro $^{1 *}$, Aodah Diamah ${ }^{1}$, Ibnuh Sakti $^{1}$, Ridwan $^{1}$, Nurhaliza $^{1}$, \\ Imam Firmansyah ${ }^{1}$, and Setia Budi ${ }^{2}$ \\ ${ }^{1}$ Department of Electrical Engineering, Faculty of Engineering, Universitas Negeri Jakarta, Jakarta Timur, \\ Indonesia \\ 2 Department of Chemistry, Faculty of Mathematics and Natural Sciences, Universitas Negeri Jakarta, Jakarta \\ Timur, Indonesia \\ *Corresponding author. Email: myusro@unj.ac.id
}

\begin{abstract}
The increase in air pollution in Indonesia is a serious problem. Health problems due to air pollution can cause damage to the lungs or cause eye irritation. One of the harmful gases contained in exhaust emissions is carbon monoxide (CO). This study aims to design a system capable of detecting and monitoring CO polluting gases using CO gas sensors and camera sensors. This system is designed using a drone/quadcopter so that detection can be carried out dynamically (mobile detection) to measure in locations that are dangerous or difficult to reach by humans. This system is also designed based on the Internet of Things (IoT) where measurement results can be monitored in real-time remotely via smartphones and websites. In the designed system, the process of measuring the concentration of CO polluting gas is carried out using the MQ-7 sensor, monitoring the location of CO polluting gas measurements using the OV5647 camera, and the system utilizing the GPS module to determine the measurement location point. This system has not been completed in its entirety, this paper describes the system design, circuit schematic design, initial measurements on sensors, testing on quadcopter motors, and website display design. Later, in the results of the research, the results of the detection and monitoring of $\mathrm{CO}$ polluting gas concentrations will be displayed on a web page in the form of an interactive map that can be accessed online by the public.
\end{abstract}

Keywords: Gas Detection, IoT, Monitoring System

\section{INTRODUCTION}

Data from The Center for Research on Energy and Clean Air (CREA), an average of 38,000 people each year in Indonesia is estimated to die from lower respiratory infections [1]. There is strong evidence that exposure to air pollution can increase the risk of severe COVID-19 infection leading to death [2]. In this regard, Greenpeace urges the provincial government of DKI Jakarta to add air quality monitoring stations that can represent Jakarta as a whole, provide an integrated public transportation system, and coordinate with the governments of West Java and Banten to control transboundary air pollution. This is in line with the 11th goal of the Sustainable Development Goals (SDGs), which is to build inclusive, safe, durable, and sustainable cities and settlements [3].

Health problems due to air pollution can cause damage to the lungs or cause eye irritation. One of the harmful gases contained in exhaust emissions is carbon monoxide (CO). The toxic effect of $\mathrm{CO}$ gas on the human body is caused by the reaction between $\mathrm{CO}$ and hemoglobin $(\mathrm{Hb})$ in the blood. By paying attention to the dangers of the effects of excessive carbon monoxide gas levels on health, a tool is needed that can measure and monitor the value of carbon monoxide gas levels in real-time in urban and residential areas, both easily accessible and difficult to reach. Measurement and monitoring of $\mathrm{CO}$ levels are important as information material for further analysis by the authorities to make certain solutions/policies to make cities healthier. 
Pollutant gas emission monitoring systems are generally carried out manually using gas sensors at certain points which take a lot of time and cost [4]. A study conducted by M. Fahim Jan (2010) analyzed the dangers of $\mathrm{CO}$ poisoning in the building area, especially for workers in steel factories. $\mathrm{CO}$ detection solutions must be wireless and immediate to use, as steel mills cannot provide downtime for wiring. Jan et al proposed a $\mathrm{CO}$ poisoning prevention system based on a Wireless Sensor Network (WSN) that continuously detects $\mathrm{CO}$ levels in certain spaces and automatically activates a countermeasure system to reduce $\mathrm{CO}$ concentration levels [5]. In his research on the dangers of $\mathrm{CO}, \mathrm{N}$. Turja said that carbon monoxide (CO) is a toxic gas and an environmental pollutant [6]. Its detection and control in residential and industrial environments are necessary to avoid human health problems. CO sensing technology with short-range detection capability is required under highly optimal conditions. The most effective $\mathrm{CO}$ sensors, then, can be used in networks Cyber-Physical Systems (CPS) to provide monitoring and control pathways real-time in both industrial and household environments.

In addition to several studies on $\mathrm{CO}$ detection carried out indoors or semi-enclosed, there are also studies that measure CO levels in open areas (outdoor). This study utilizes a device drone/quadcopter as a measure of the value of carbon monoxide gas levels in the air [7]. In this study, a drone/quadcopter was designed using Arduino Mega2560 as the main data processor to retrieve the MQ-7 gas sensor data which is then transmitted via the YS-1020 RF module to the ground segment and will enter the data logger using the Microsoft Access database. Next is the research by Priyanta, et al. (2016) who designed a drone/quadcopter using a Tracking Point System that can move automatically based on the position of the Global Positioning System (GPS). This drone/quadcopter is supported by a semiconductor gas sensor. The results of the gas sensor readings are processed on the STM132F4 microcontroller and then sent to the Raspberry 2 using the serial port TX (transmitter) and presented on the web server on Raspberry 2 [4]. Research conducted by Ibnuh Sakti, et al (2020) has created a system for detecting carbon monoxide gas levels based on the Internet of Things (IoT) using a quadcopter [8]. This study has several limitations, including that measurement data is only stored on the Raspberry Pi system, so the data cannot be accessed when the system is inactive. In addition, the tool made is not equipped with a camera sensor that is useful for monitoring the condition of the area where $\mathrm{CO}$ levels are being detected.

From several studies that have been described previously, it can be concluded that the detection of $\mathrm{CO}$ as a pollutant harmful to health is very important to be designed and developed further. Existing CO detection systems are used for indoor (houses, buildings, or factories) as well as outdoor (urban and residential) applications. The development of transducer sensors, especially those related to $\mathrm{CO}$ sensors, is also increasingly modern and sophisticated, including the use of a microcontroller-microprocessor, as well as the use of IoT, opening opportunities for technological innovations to detect $\mathrm{CO}$ pollutant gases. The selection of the model mobile detection aims to make moving measurements in areas that are difficult to reach or even tend to endanger human safety. Electronic devices that can be used for mobile detection are drones/quadcopters which are one type of Unmanned Aerial Vehicle (UAV) or an unmanned aircraft that has 4 propellers as its propulsion. In this research design, when this system has been built, the detection and monitoring system device will be placed on the drone/quadcopter that will move over the object/area whose $\mathrm{CO}$ will be measured

\section{METHODS}

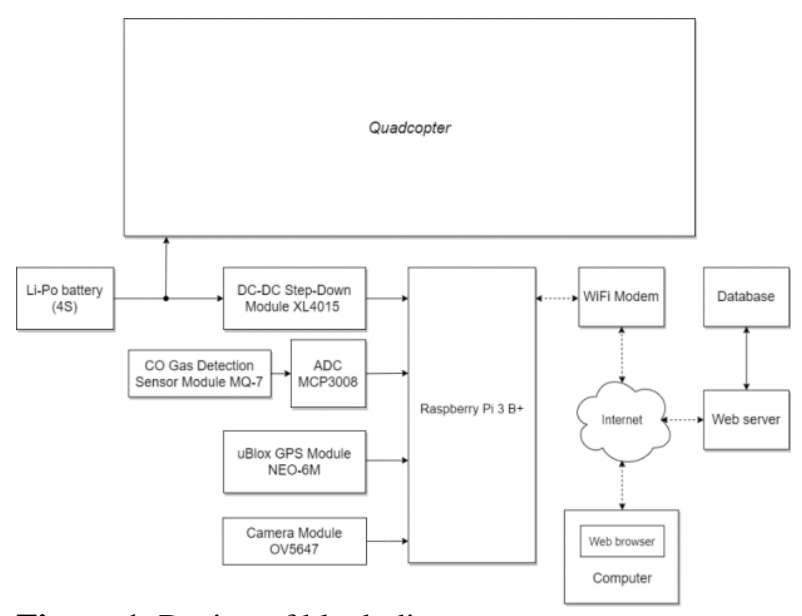

Figure 1. Design of block diagram system.

The research method used is a research and development (R\&D) model from Borg and Gall [9], wherein in this study only 4 steps of $R \& D$ research were used. The first stage is the information gathering stage, which includes searching the literature related to the research. Literature is obtained from various scientific publication articles from proceedings and reputable national and international journals. The contents of the scientific literature were analyzed to obtain important information about the research objectives, the hardware and software used, system testing methods and the conclusions of the research results. Next, the second is the planning stage, namely determining the parameters to be measured in the 
gas level monitoring system, where there are 3 steps carried out at this stage, namely (i) system block diagram design, (ii) input and output planning system, and (iii) system flow diagram planning. The design of the system block diagram is carried out to facilitate the identification of sub-systems and to know the mapping in planning input and output. The design of the block diagram system is shown in Figure 1.

The functions of each block in Figure 1 are (i) a quadcopter with frame type F450 and a RadioLink Pixhawk flight controller which is implemented as a tool to perform mobile detection in the process of collecting data on carbon monoxide gas concentrations in the air, (ii) Li-Po batteries. ONBO $5200 \mathrm{mAh} 25 \mathrm{C} 4 \mathrm{~S}$ is used to supply power to all modules used in the quadcopter system, (iii) Raspberry Pi 3 Model B+ with 64-bit quad-core processor running at $1.4 \mathrm{GHz}$, dual-band $2.4 \mathrm{GHz}$ is used as the main processor of the system monitoring carbon monoxide gas and serves to send monitoring results to the web server, (iv) step-down DC-DC module XL-4015 with a voltage of 1.25 - $36 \mathrm{VDC}$ (adjustable) and a maximum current of $5 \mathrm{~A}$ is used as a voltage reducer from a Li-battery.

Po to supply the Raspberry Pi 3 B+, (v) the MQ-7 sensor module is used to detect and monitor carbon monoxide gas concentrations in the range of $20-2000$ parts per million, (vi) the MCP 3008 IC which is a will Convert Analog to Digital $r$ with 10 bit resolution, used to convert analog signal output from sensor module MQ-7 into digital signal for processing on Raspberry Pi $3 \mathrm{~B}+$, (vii) GPS module u-blox NEO-6M as GPS Receiver used to determine the carbon monoxide gas measurement location point which will be read and processed on the Raspberry Pi 3 B+, (viii) the OV5647 camera module is a Raspberry $\mathrm{Pi}$ camera that is used in the recording process to determine the condition of the measurement location via a live video stream, (ix) the wi-fi modem functions as internet access on the Raspberry Pi 3 B + to send data to the web server, (x) the web server functions to receive requests sent via a web browser and the Raspberry Pi 3 B+ as a client, (xi) the database as data storage results measurement on the server, and (xii) a web browser on the computer as an access web server to request information on the results of monitoring the concentration of carbon monoxide gas.

After carrying out the planning stages of the system block diagram as well as input and output design, the next step is to design a system flow diagram that describes the system's performance procedures logically. The system flow diagram is shown in Figure 2.

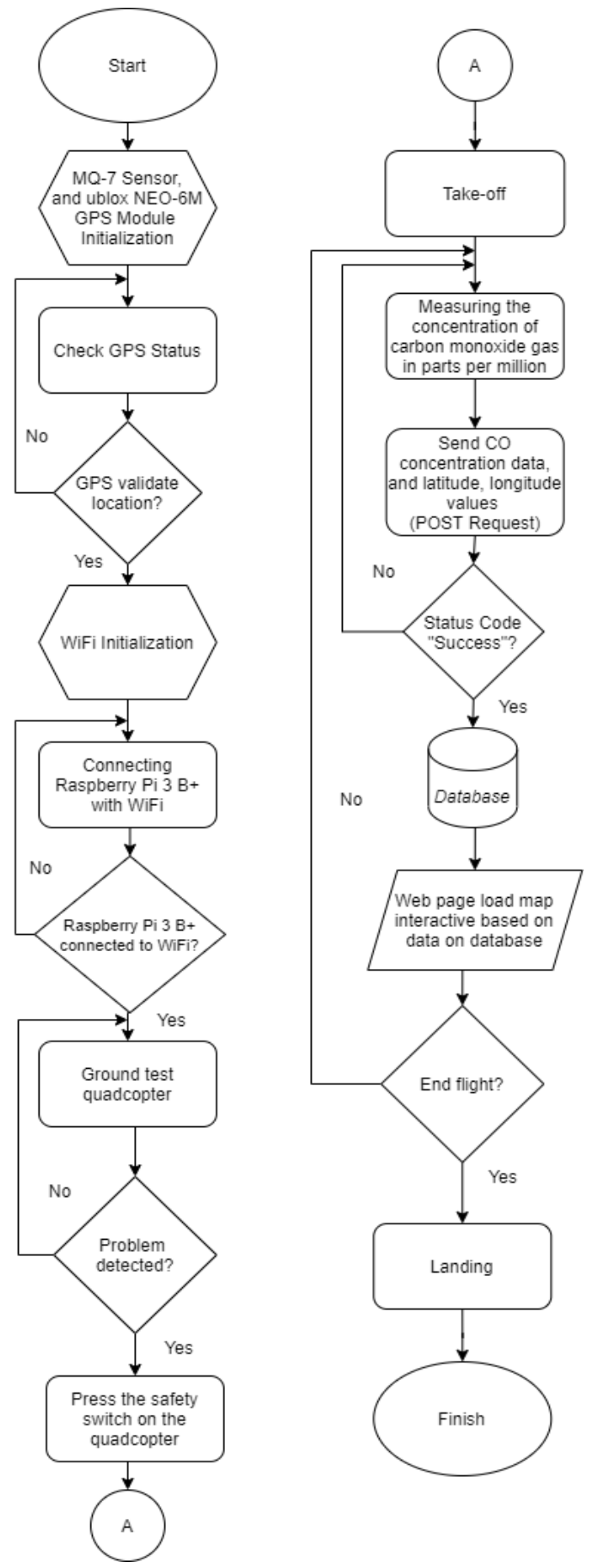

Figure 2. The flowchart system.

Next research step is the development stage, where there are two things to do at this stage, namely (i) design hardware which includes PCB design process assembly based on system block diagrams, and (ii) page design 
web including the creation process web which will be integrated with devices hardware to display the results monitoring of CO pollutant gas. After the development stage has been carried out, the next step is the testing stage sub-system and overall system. Sub-system testing is carried out on each sub-system device, starting with reading the concentration of carbon monoxide gas using the MQ-7 sensor with a range of 20-100 parts per million (ppm) and measuring the output voltage of the MQ-7 sensor during the reading.

Then to determine the accuracy and error of sensor readings, calibration is carried out on the Laboratory Gas Analyzer by spraying pure carbon monoxide gas with a certain concentration. Next, the ublox NEO6-M GPS module was tested which aims to determine the accuracy of location readings. This test is carried out by comparing the location readings from the ublox NEO6-M GPS module with the location readings from the reference GPS device. After testing each sub-system device is carried out and has the results in accordance with the expected results, the next process is the system testing stage. System testing is in the form of monitoring the concentration of carbon monoxide gas in the air by flying a quadcopter at the test location points. In this stage, 3 test locations are determined, then viewing the results monitoring on a web page in the form of an interactive map.

\section{RESULTS AND DISCUSSION}

The system designed in this study uses the Raspberry Pi $3 \mathrm{~B}+$ as the main controller. The Raspberry Pi 3 Model $\mathrm{B}+$ is the latest version of the minicomputer released by the Raspberry Pi as a development of the previous version of the Raspberry Pi [10].

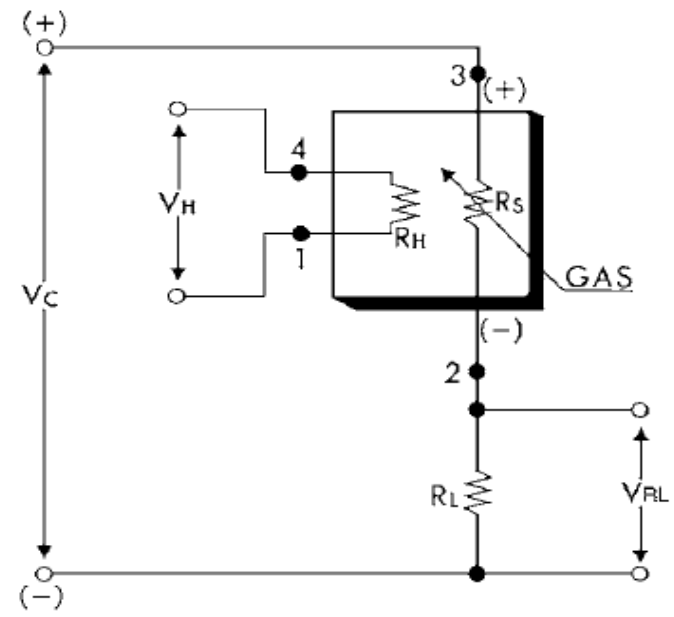

Figure 3. Schematic design of the MQ-7.

Raspberry Pi uses a System on A Chip (SoC) from Broadcom BCM2835 to BCM2837 (Raspberry Pi 3), also includes ARM1176JZF-S MHz processor and even 1.2GHz 64-bit quad-core ARMv8 CPU for Raspberry Pi 3, Video Core IV GPU, and RAM capacity up to 1 GB. On the Raspberry Pi, data storage is designed not to use a hard disk or solid-state drive, but to rely on an SD card (SD memory card) for booting and long-term storage.

The detection and monitoring system $\mathrm{CO}$ pollutant gas in this design uses the MQ-7 sensor as a sensor to detect CO gas [11] and the OV5647 camera sensor to monitor the location of $\mathrm{CO}$ gas measurements in realtime [12]. The MQ-7 sensor consists of micro Al2O3 as a ceramic tube, tin dioxide $(\mathrm{SnO} 2)$ as the sensor layer, electrodes and heater coated with plastic, and stainless steel in the form of a net on the top of the sensor to avoid corrosion on the inside of the sensor [13]. If CO gas is detected, the output voltage on the sensor will increase, so that the gas concentration will decrease and a deoxidation process occurs. Sensor MQ-7 requires the heater voltage (power heater) at $5 \mathrm{~V}$ during the heating process, $1.4 \mathrm{~V}$ during the sensing process. Figure 3 shows a circuit schematic using the MQ-7 sensor.

The schematic design of the MQ-7 sensor circuit with Raspberry Pi $3 \mathrm{~B}+$ in this study is shown in Figure 4.

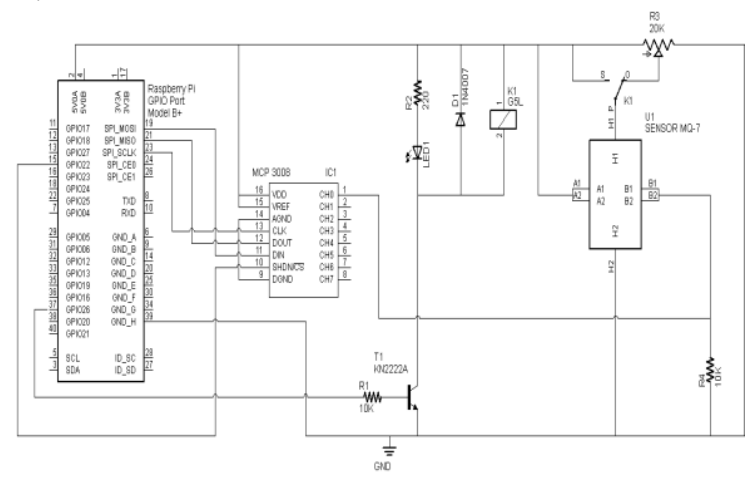

Figure 4. Schematic design of the MQ-7 sensor circuit with Raspberry Pi 3 B+.

Table 1. MQ-7 sensor test results.

CO Gas Concentration

on Carbon Monoxide Me-

ter (Smart Sensor Brand) in (ppm)

MQ-7 Sensor Output Voltage (Volt)

\begin{tabular}{|c|c|}
\hline in (ppm) & \\
\hline 20 & 1,23 \\
\hline 30 & 1,43 \\
\hline 40 & 1,65 \\
\hline 50 & 1,79 \\
\hline 60 & 1,90 \\
\hline 70 & 2,06 \\
\hline 80 & 2,18 \\
\hline 90 & 2,26 \\
\hline 100 & 2,44 \\
\hline
\end{tabular}


The initial stage of this research has been testing the MQ-7 sensor, which aims to determine the relationship between the carbon monoxide gas concentration value read in parts per million with the MQ-7 sensor output voltage. Testing the MQ-7 sensor is carried out by installing the MQ-7 sensor along with a Carbon Monoxide Meter (Smart Sensor Brand) into a closed box with dimensions of $11 \mathrm{~cm} \times 11 \mathrm{~cm} \times 17 \mathrm{~cm}$, then inserting a sample of carbon monoxide gas with a concentration range of 20-100 ppm produced from antioxidant (mosquito coils). During the process of reading the carbon monoxide gas concentration, the MQ-7 sensor output voltage is measured and then recorded to obtain a graph along with a linear regression equation that shows the relationship between the carbon monoxide gas concentration value in ppm (parts per million) and the MQ-7 sensor output voltage. The results of the MQ-7 sensor test are shown in Table 1 .

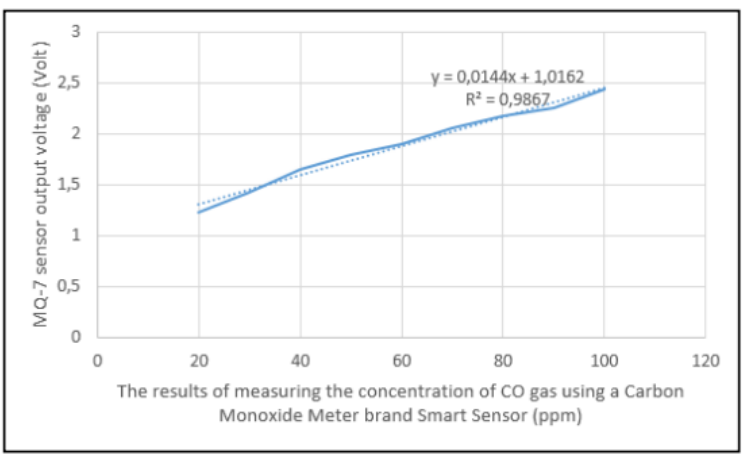

Figure 5. Graph of the relationship of CO gas concentration values measured using smart sensors with MQ-7 sensor output voltage.

Furthermore, graphs and linear regression equations that show the relationship between the concentration of carbon monoxide (ppm) and the MQ-7 sensor output voltage are shown in Figure 5 below.
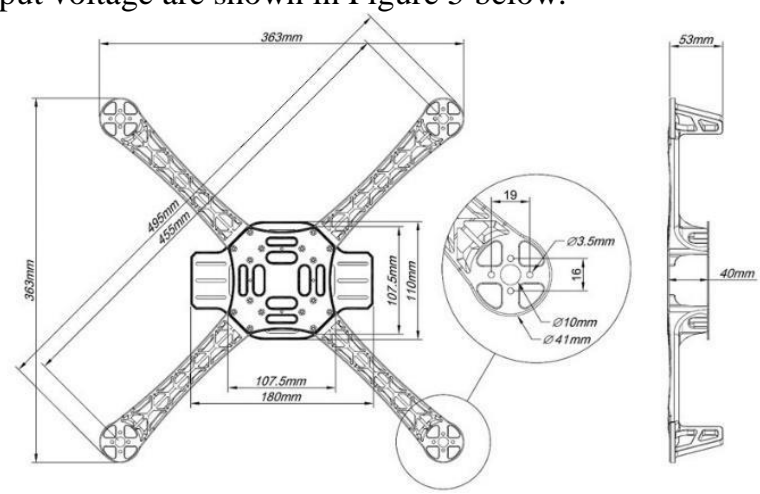

Figure 6. Dimensions of the quadcopter frame F450.
In this system design, the quadcopter used is a flight controller Radiolink Pixhawk with a frame type F450 (arm length: $450 \mathrm{~mm}$ ) whose dimensions are shown in Figure 6.

The quadcopter uses radio control as a controller with Turnigy TGY i6S as a transmitter (remote control), and Turnigy TGY iA6C as a receiver, as well as Telemetry Radio 3DR $433 \mathrm{MHz}$ to connect the quadcopter to the Ground Control System (GCS), namely component that serves to collect all information about the status of the UAV and allows to send appropriate commands to a predefined mission [14]. As a navigation device, the quadcopter is accompanied by a ublox NEO-M8N GPS module built-in Compass. Furthermore, as a drive quadcopter, the motor is used brushless SunnySky X2216 KV: 880with propeller APC1047 type, and ESC 30A. Then LiPo ONBO 4S (14.8) 5200mAH 25C battery as a power source. The test report for the motor is brushless SunnySky X2216 shown in Table 2.

Table 2 describes the motor capabilities brushless according to the propeller and power applied to the motor brushless. Based on the test report and the equipment used in the quadcopter, data shows that 1 motor brushless with a current of 29.3 Ampere has a thrust of 1700 grams, so the total capability of 4 motors brushless is $4 \times 1700$ grams with a current of 117.2 Ampere, which is 6800 grams (6.8 kilograms).

Furthermore, on the $\mathrm{CO}$ pollutant gas detection device, the MQ-7 sensor is used which is integrated with the MCP3008 as a 10-bit ADC to carry out the detection and monitoring of $\mathrm{CO}$ pollutant gas, the device also includes a GPS ublox NEO-6M to read the point of the measurement location. In this study, the system can not only monitor the concentration of carbon monoxide gas at a location, but also can monitor the condition of the area by monitoring visually using the OV5647 camera module. As a processor, the Raspberry Pi 3 Model B+ is used to process the data monitoring.

This system implements Internet of Things (IoT). System integration with cloud computing is an important point in this research. In its application, the data monitoring that has been processed on the Raspberry Pi $3 \mathrm{~B}+$ will be sent to the database server for further display on a page web that can be accessed publicly via the internet. The web was created by implementing a Geographic Information System (GIS), which is a computer-based information system for storing, managing, and analyzing, and recalling geographically referenced data [13]. The web page will load an interactive map that shows the location points in the form of markers with the concentration value of carbon monoxide gas which will be displayed on the pop-up of each marker according to the point where 
Table 2. Test report for the motor brushless Sunny Sky XS2216

\begin{tabular}{|c|c|c|c|c|c|c|}
\hline Prop. (inch) & Voltage (V) & Amp. (A) & Thrust (g) & Watts (W) & Efficiency $(\mathrm{g} / \mathrm{W})$ & RPM \\
\hline \multirow{19}{*}{ APC1047 } & \multirow{19}{*}{14.8} & 0.6 & 100 & 8.88 & 11.26 & 2527 \\
\hline & & 1.4 & 200 & 20.72 & 9.65 & 3517 \\
\hline & & 2.3 & 300 & 34.04 & 8.81 & 4236 \\
\hline & & 3.5 & 400 & 51.8 & 7.72 & 4784 \\
\hline & & 4.8 & 500 & 71.04 & 7.04 & 5310 \\
\hline & & 6 & 600 & 88.8 & 6.76 & 5757 \\
\hline & & 7.9 & 700 & 116.92 & 5.99 & 6200 \\
\hline & & 9.4 & 800 & 139.12 & 5.75 & 6621 \\
\hline & & 11.1 & 900 & 164.28 & 5.48 & 7020 \\
\hline & & 13 & 1000 & 192.2 & 5.20 & 7318 \\
\hline & & 14.6 & 1100 & 216.08 & 5.09 & 7652 \\
\hline & & 17.1 & 1200 & 253.08 & 4.74 & 7990 \\
\hline & & 19 & 1300 & 281.2 & 4.62 & 8287 \\
\hline & & 21.2 & 1400 & 313.76 & 4.46 & 8505 \\
\hline & & 23.2 & 1500 & 343.36 & 4.37 & 8860 \\
\hline & & 26.1 & 1600 & 386.28 & 4.14 & 9120 \\
\hline & & 29.3 & 1700 & 433.64 & 3.92 & 9405 \\
\hline & & 35 & 1900 & 518 & 3.67 & 10082 \\
\hline & & 38.4 & 2130 & 568.32 & 3.75 & 10476 \\
\hline
\end{tabular}

the carried-out monitoring is. On the web page, an interactive map is used to display the location points for measuring carbon monoxide gas concentrations by displaying the concentration value in ppm (parts per million) in the form of a pop-up on the map marker (Figure 7). Later, this web page will also display pictures/videos of realtime measurement locations obtained from camera sensors placed on the drone.

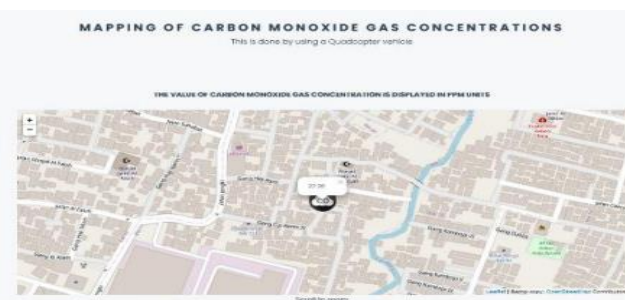

Figure 7. Design of web page for display of CO pollutant gas measurement location points.
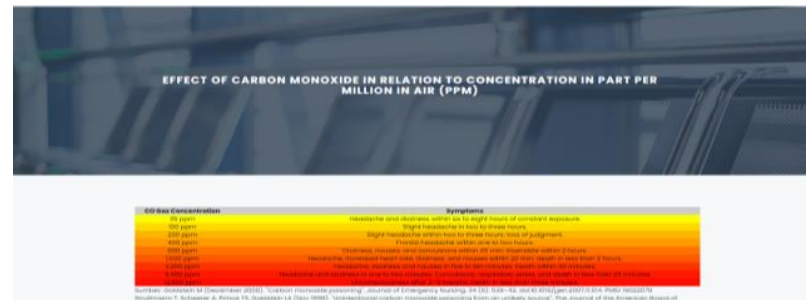

Figure 8. Design web page for information display effect $\mathrm{CO}$ gas pollutants for health.

The next web page display contains information about the harmful effects of $\mathrm{CO}$ pollutant gas on health. This is useful for providing information to the relevant community symptoms that arise in humans due to exposure to $\mathrm{CO}$ gas in the concentration range of $35-12,800$ ppm. Design web pages to load information to the health effects of CO gas is shown in Figure 8.

To get Internet access that will be used during the process of sending data to the database server, the system 
is plugged in the modem integrated with Raspberry Pi 3 $\mathrm{B}+$. The power source for the $\mathrm{CO}$ pollutant gas detection device is supplied using a Li-Po battery with a reduced voltage value using the Step-Down DC-DC XL4015 module to $5 \mathrm{~V}$. In the $\mathrm{CO}$ pollutant gas monitoring device and camera module, used case is to protect components that are susceptible to dirt or impact. This device is installed on the bottom of the quadcopter using a mounting bracket with the MQ-7 sensor facing downwards.

\section{CONCLUSION}

This research was conducted by designing a $\mathrm{CO}$ pollutant gas detection and monitoring system with a model mobile detection that aims to reach difficult terrain, and even dangerous to human health. Due to the Covid-19 pandemic, this research has not been completed in its entirety, especially about data collection in the field. This paper describes the system design, circuit schematic design, initial measurements on sensors, testing on quadcopter motors, and website display design. The design of this system uses the MQ-7 sensor to detect CO gas, the OV5647 camera sensor to monitor the location of CO gas measurements in real-time, and the ublox NEO-6M GPS to get the location points for CO gas measurements. In processing measurement data, this system will use a minicomputer Raspberry Pi 3 Model B+ which is used as a web server to store measurement data into a database. Besides being stored on the Raspberry $\mathrm{Pi}$, the measurement results are also stored on the web server so that they can be accessed at any time.

The choice of type Unmanned Aerial Vehicle (UAV) technology quadcopter in this study is due to the high flexibility of the quadcopter, allowing the integration of various technologies that require high mobility. The implementation of UAV technology quadcopter technically requires the selection of specifications based on capabilities, as well as the parameters to be met. The result of the design of this system is that the detection of CO pollutant gas in urban/residential areas can be carried out safely and can reach difficult locations. The results of the detection and monitoring of $\mathrm{CO}$ pollutant gases will be displayed on a web page in the form of an interactive map that can be accessed online by the public.

\section{ACKNOWLEDGMENT}

This work was supported by Research Institutions and Community Service (LPPM) Universitas Negeri Jakarta and Faculty of Engineering, Universitas Negeri Jakarta. The authors would like to thank for some anonymous reviewers for their constructive comments and insightful suggestions that improved the quality of this paper.

\section{REFERENCES}

[1] BBC News Indonesia 2020 Kualitas udara Jakarta selama PSBB membaik, namun tingkat polutan berbahaya PM 2.5 tetap konsisten[Online] Available: https://www.bbc.com/indonesia/indonesia52755813

[2] X. Wu, R. C. Nethery, M. B. Sabath, D. Braun, and F. Dominici 2020 Exposure to Air Pollution and COVID-19 Mortality in the United States: A Nationwide Cross-Sectional Study.

[3] SDGs 2021 Tujuan dan Target 11 SDGs [Online] Available: https://www.sdg2030indonesia.org/page/19-tujuan-sebelas

[4] I. F. Priyanta, M. Rivai, and R. Dikairono 2016 Pemetaan Distribusi Gas Polutan Menggunakan Quadcopter Berbasis Autonomous Waypoint Navigation Jurnal Teknologi ITS, vol. 5, no. 2, pp. 154159, 2016, doi: 10.12962/j23373539.v5i2.16238

[5] M. F. Jan, Q. Habib, M. Irfan, M. Murad, K. M. Yahya, and G. M. Hassan 2010 Carbon Monoxide Detection and Autonomous Countermeasure System for a Steel Mill using Wireless Sensor and Actuator Network Proc. - 2010 6th Int. Conf. Emerg. Technol. ICET 2010, no. October, pp. 405-409, 2010, doi: 10.1109/ICET.2010.5638502

[6] T. Nandy, R. A. Coutu, and C. Ababei 2018 Carbon Monoxide Sensing Technologies for Next-Generation Cyber-Physical Systems Sensors (Switzerland), vol. 18, no. 10, 2018, doi: 10.3390/s18103443

[7] A. A. Saputra and A. Dharmawan 2013 Rancang Bangun Quadcopter untuk Pemantauan Kadar Karbon Monoksida di Udara IJEIS (Indonesian J. Electron. Instrum. Syst., vol. 3, no. 1, pp. 11-22, 2013, doi: 10.22146/ijeis.3835

[8] I. Sakti, M. Yusro, and A. Diamah 2021 A Quadcopter for Monitoring System of Carbon Monoxide Levels Based on Internet of Things in International Conference on Intelligent Technologies (CONIT), 2021, pp. 1-5

[9] M. D. Gall, Joyce P. Gall, and Walter R. Borg 2007 Educational Research: An Introduction, 8th Edition. Pearson Education, Inc

[10] Raspberry Pi Foundation, 2020 Raspberry Pi 3 Model B+ Product Brief Raspberry Pi, p. 2837

[11] B. K. Nuhu, O. M. Olaniyi, I. A. Dauda, and C. Onyema, 2020 Smart Room Carbon Monoxide Monitoring and Control System Journal Adv Comp Eng Tech, vol. 6, no. 1, pp. 0-7, 2020

[12] G. Salem et al. 2020 Digital video recorder for Raspberry PI cameras with multi-camera synchronous acquisition HardwareX, vol. 8, p. e00160, 2020, doi: 10.1016/j.ohx.2020.e00160. 
[13] Henan Hanwei Electronics 2018 MQ-7 Carbon Monoxide Datasheet

[14] D. Perez-Rodriguez, I. Maza, F. Caballero, D. Scarlatti, E. Casado, and A. Ollero 2012 A Ground Control Station for a Multi-UAV Surveillance System A Ground Control Station for a Multi-UAV Surveillance System : Design and Validation in Field Experiments Journal Intell. Robot. Syst., no. January, 2012, doi: 10.1007/s10846-012-9759-5 